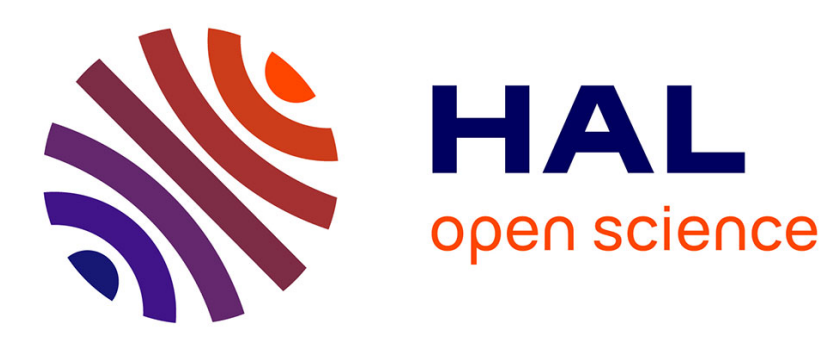

\title{
China's Transition to a Digital Currency: Does It Threaten Dollarization?
}

\author{
Ahmet Faruk Aysan, Nawaz Farrukh
}

\section{To cite this version:}

Ahmet Faruk Aysan, Nawaz Farrukh. China's Transition to a Digital Currency: Does It Threaten Dollarization?. 2021. hal-03364939

\section{HAL Id: hal-03364939 \\ https://hal.science/hal-03364939}

Preprint submitted on 5 Oct 2021

HAL is a multi-disciplinary open access archive for the deposit and dissemination of scientific research documents, whether they are published or not. The documents may come from teaching and research institutions in France or abroad, or from public or private research centers.
L'archive ouverte pluridisciplinaire HAL, est destinée au dépôt et à la diffusion de documents scientifiques de niveau recherche, publiés ou non, émanant des établissements d'enseignement et de recherche français ou étrangers, des laboratoires publics ou privés. 


\title{
China's Transition to a Digital Currency: Does It Threaten Dollarization?
}

\begin{abstract}
This article provides a detailed introduction to China's launching of a digital currency. We conduct a comparative analysis concerning whether digital currency is a more stable and reliable currency than cryptocurrency and investigate whether a digital renminbi (or yuan) could replace the US dollar as a medium of exchange in international transactions. China has gained a first-mover advantage by rolling out a central bank digital currency (CBDC). But the outcome will depend on the US response as well as the future evolution of the US and Chinese economies. Most other articles on this topic focus on domestic use of the Chinese CBDC. But this study is unique in analyzing the prospects of a digital renminbi as a replacement for the US dollar in international commerce.
\end{abstract}

Keywords: China, cryptocurrency, digital yuan, People's Bank of China, US.

JEL Classifications: E42, E58, G28.

\author{
Ahmet Faruk Aysan \\ Hamad Bin Khalifa University, \\ Professor \& Program Coordinator, PhD in Islamic Finance and Economy \\ College of Islamic Studies, Qatar Foundation \\ Orcid: 0000-0001-7363-0116 \\ aaysan@hbku.edu.qa
}

Farrukh Nawaz Kayani

Department of Economics

College of Economics and Management

Al Qasimia University

Sharjah, United Arab Emirates

fkayani@alqasimia.ac.ae 


\section{China's Transition to a Digital Currency: Does It Threaten Dollarization?}

\section{Introduction}

Over the past decade, the importance of cryptocurrency, especially Bitcoin, has rapidly increased. The crypto market has a great deal of potential, but its highly decentralized nature poses threats as well. The absence of a regulatory authority for monitoring and overseeing operations associated with such digital transactions makes cryptocurrency a high-risk investment. Because it is backed by only a handful of investors or by sentiment generated in the market, crypto has a volatile nature that foreshadows the instability and frailty it can introduce into the economic system (Aysan et al., 2021). Financial experts see cryptocurrency as the biggest challenge to the financial system and believe that immediate measures are needed to retain control of that system (Aysan et al. 2020). To maintain control of this system and limit any shift in it, several central banks have introduced a national digital currency (Auer, Cornelli, \& Frost, 2020). However, many countries still do not support the concept of a digital currency, as they see it as farfetched and claim that introducing one will only make the financial system more vulnerable to potential cybersecurity and financial stability threats (Parn \& Edwards, 2019).

Many economists hold that the basic concept of money that has existed for centuries is being challenged by the introduction of digital currency. In addition, the adoption of digital currency by many developing countries is impeded by their lack of technology and the infrastructure required for it. The level of investment needed for a digital transformation of the entire financial system is enormous and not within the capacity of every country. The transformation demands not only financial resources but also an understanding of the modern world as well as experience with the dynamics of the financial system and the concomitant technological advancements (Ducas \& 
Wilner, 2017). This implies that central banks will be unable to unlock the potential of digital currency in the absence of the necessary technology. Apart from the technology aspects, some central banks are also keen to introduce digital currency to maintain their financial prerogatives over other countries, and other less credible central banks are concerned about losing control over the economy in their country.

A central bank digital currency (CBDC) plays all the functions of money: it is a liability for the central bank, it is used as a medium of exchange, and it can be used as a store of value. As the world gradually moves toward being cashless, access to a legal tender in the absence of physical money is guaranteed by the issuance of a digital currency by a country's central bank. What makes CBDCs so lucrative and trustworthy is that they are available from a credible authority that can ensure their value. Moreover, through their database for electronic and systematic record-keeping, CBDCs have the potential to help governments regulate the financial practices of individuals. Keeping track of all the transactions that take place also helps to prevent fraudulent and criminal activities, guaranteeing increased safety for the public. It can also help central banks in implementing an optimal monetary policy, identifying problem areas, and enforcing the macroprudential policies needed to ensure price and financial stability (Aysan et al., 2014, 2015). The adoption of a digital currency can also reduce the expense for central banks of transactions and printing physical money, enabling domestic and international transactions to occur at minimum risk and without too much cost.

Central banks that plan to issue a digital currency intend to make it widely accessible to all kinds of businesses and individuals, in the hope that it will become an acceptable medium of exchange. Many researchers, however, claim that when central banks have too much authority over the currency, they raise concerns among other actors in the financial system. Centralized authority 
makes the system rigid and prevents free-flowing movement, which can have far-reaching repercussions for consumers and the economy.

Discussions about CBDCs in recent years have been connected to the rise in privately issued cryptocurrency, such as Bitcoin. In a way, increasing interest in private cryptocurrency has driven central banks to pay more attention to the idea of CBDCs to maintain the benefit of their sovereign seigniorage rights while providing financial stability. Central banks have the authority to appreciate or depreciate the currency, and a sudden change in government policies makes businesses and individuals more prone to catastrophic risk. Hence concerns over financial stability arise when the market is dominated by private cryptocurrency.

For developing countries, the macroeconomic implications of CBDCs and other digital currencies as well as their regulatory issues are considerable. Moreover, the growth of digital currency and emoney is essential for financial inclusion. CBDCs have disrupted the international monetary system. The prevalence of systemically significant platforms could result in the emergence of transnational CBDC areas. Alternatively, countries that are digitally or socially integrated with their neighbors might experience digital dollarization (Kow et al., 2017).

In addition, in a centralized financial framework, private entities have a low level of liquidity because the central authority has the discretion to freeze anyone's finances. As shown by the Great Recession in 2008, the financial system is more vulnerable to failure when all power is vested in a single institution (Chen \& Bellavitis, 2020). To protect themselves from that eventuality, some businesses and private entities have called for decentralization of the financial system and allowing the market to determine the value of the currency, following the laws of supply and demand. Because of the rising importance of digital transactions, which have transformed the long-standing paradigms in finance, the use of physical cash in developed economies fell 2.2 percent on an annual 
basis (International Monetary Fund, 2019). In sum, CBDCs have their pros and cons, and the world is moving toward a digital era in which they appear to be a necessity for central banks, rather than an option.

As part of its effort to internationalize the renminbi and to reduce dependence on the US dollardominated financial system, the People's Bank of China (PBOC) has become the first major central bank to issue a CBDC, called the digital yuan, eRMB, or e-CNY. China is trying to take advantage of a first-mover strategy and leverage its position to promote the invoicing of trade in digital yuan. The purpose of the article is to analyze whether the Chinese CBDC has the potential to replace the US dollar in international trade and finance. First, we offer a detailed introduction on China's launching of the digital yuan. Second, we carry out a comparative analysis on why digital currency is considered more stable and reliable than cryptocurrency. Finally, we study whether the digital yuan could replace the US dollar as medium of exchange in international transactions.

Our main conclusions are as follows. China has gained a first-mover advantage by rolling out its CBDC. But the outcome depends upon the US response as well as how the US and Chinese economies evolve in the future. The US has the potential to catch up with China's digital currency because it is already a strong fintech power, and most Americans overwhelmingly conduct electronic transactions already using various technologies. This might reduce the extent to which China could capitalize on its first-mover advantage. For the digital yuan to be successfully internationalized, China would need to win the confidence of global users in the strength of the Chinese financial system and the security of the digital yuan. Most other articles on the Chinese $\mathrm{CBDC}$ focus on its domestic use, but this study is unique in analyzing the prospects for the digital yuan to replace the US dollar in global transactions. 
The rest of the article is organized as follows: section 2 describes China's launching of the CBDC, section 3 offers a detailed comparison between CBDCs and cryptocurrencies; section 4 details the challenges to the US dollar from the Chinese digital yuan, and section 5 concludes the article.

\section{China's Launching of a Central Bank Digital Currency}

Over the past few decades, the world has experienced a technological transition, creating a race in which developing and adopting the latest technology has never been more essential. The race is no longer among technology experts but has spread to countries, such that each country aims to become a superpower in technological advancement. The present dynamics in the fight for supremacy among global powers rely on how well a country performs both technologically and financially. These objectives have become even more interlinked over time. In the past, the only way a country could claim dominance over another was through its labor endowment. However, as the competition has transformed into a battle for technological advancement, this dominance has taken a new shape. The rapid technological advancements have introduced great benefits in finance, enabling the creation of digital currency by both private and public actors. The advantages of CBDCs have led many economists to claim that keeping the financial system updated according to the latest technology and under the control of a credible institution such as the central bank to maintain trust and stability in a country's economy is a potential pathway for that country to establish global dominance.

Because of this technological transition, the global economy is rapidly becoming cashless, characterized by a rise in the use of digital transactions. This change is due to the convenience and cost savings associated with digital transactions compared to those with physical cash. This new

mode of transactions is facilitated by the issuance of CBDCs. Economists claim that countries that 
are among the early issuers of digital currencies can make their mark in global digital finance, and China has taken the lead in doing so. The PBOC has announced a goal of having more than a billion users before any other country can make substantial strides toward developing a CBDC of its own (Hoffman et al., 2020).

Table 1. Countries in which retail CBDC/digital currencies have been launched or are being piloted or researched

\begin{tabular}{l|ll} 
& The Bahamas (sand & \\
dollar) & \\
Cambodia (bakong) & \\
& Eastern Caribbean (DCash) (comprising St. Kitts and Nevis, Saint Vincent and the \\
Grenadines, Saint Lucia, Grenada, Dominica, Caribbean, and Antigua and Barbuda)
\end{tabular}

Source: (Canton, 2021)

The Chinese government, facing increased pressure from the US government and its influence on the global economy, feared being targeted with economic sanctions by Donald Trump, one of the most unorthodox US presidents, who created many barriers to China's financial digitization (Lo, 
2021). In 2017, the Chinese government took a different route, which led to the introduction of electronic payment with digital currency (DCEP), backed by the PBOC. In 2020, as the world was preoccupied with tackling the global coronavirus pandemic, which had emerged from China, the Chinese government was conducting trials of its digital currency. China's public sector has invested a great deal in the technology and infrastructure that drive digital transactions, so this kind of transition could occur rapidly (Ward \& Rochemont, 2019). The value of DCEP is determined by the value of the renminbi (RMB) in a one-to-one ratio. China launched its digital currency in four cities as a pilot project in April 2020 and then expanded it to 28 major cities in August 2020. In 2021 China tested the digital yuan in additional major cities, including Beijing and Shanghai, with the goal of broad general circulation in 2022.

The DCEP framework is described as consisting of "one CBDC, two databases, and three centers." "One CBDC" refers to the DCEP issued by the Chinese government. The "two databases" refer to the two-tiered system in which the DCEP operates (Lee, Yan, \& Wang, 2021), such that the central bank does not issue digital currency to the public directly. Rather, it issues the currency first to smaller commercial banks, which then issue it to its customers. Hence, the first database is that of the DCEP issued by the PBOC, and the second is the commercial bank database. The "three centers" refer to the three data centers on which the DCEP relies at its back end for regulation. The first controls the registration process, with which the government manages the data and identity of each user. Then, the second maintains records on the amount of digital currency owned by a private entity and documents its transaction history. The government plans to use this platform to keep track of all the transactions that take place to prevent criminal and fraudulent activity. The third is the analytical center, which evaluates and analyzes the purpose of the transactions and stores of money, as all kinds of surveillance are employed. Because of its ability to identify patterns that 
can affect the flow of money in the economy, the analytical center directly coordinates with the committee that formulates monetary policy. As a result, the committee can implement the optimal monetary policy, further enabling the government to achieve its targets expediently. Monetary policy can also be maneuvered to address any kind of projected disruptions in the value of the currency, giving the government and the central bank a firmer grip over the system (Davoodalhosseini, 2021). The division of responsibility, therefore, helps to develop a wellorganized system for the purpose of coordinating the shift to a digitized financial system.

The goal of the Chinese government is to reduce the power of private entities that offer digital transaction services, such as WeChat Pay and Alipay (Kiff et al., 2020). The success of these companies demonstrated the rising demand for digital currency and the strong potential for a market in it. Hence, the Chinese government seeks to seize this opportunity and to replace the fiat currency with a digital one that is universally accessible. To further facilitate the dissemination of the digital currency, China's research and development sector has enabled digital transactions without an internet connection.

DCEP can have huge ramifications for the world in terms of the efficient surveillance of transactions, which enables the creation of the largest database of financial transactions that are centrally governed (Hoffman et al., 2020). With the help of this database, China will be capable of keeping track of changing economic trends in the global market and the value generated by each good produced. This will allow it to focus its production capacity on specific goods, giving it a distinct advantage over other countries. Furthermore, it will also be able to monitor transactions, correct irregularities in the system, and keep an eye out for criminal activities in order to prevent fraud and to maintain economic stability (Kaiser, Jurado \& Ledger, 2018). China's firm grip on the global market is a worrying sign for liberal democracies, which are aware of the threat posed 
by China's possession of such great power and influence over the economy. Despite the concerns of countries such as the United States, which are aware of this quandary, China appears to be leapfrogging over its competitors in terms of all technological innovations.

China is a pioneer in financial development, and its adoption of advanced technology enables the prevalence of DCEP in the Chinese market. Little disagreement has arisen about the kind of influence of Chinese manufacturers over the global market. Hence, the moment when the Chinese currency dominates the world economy might not be far away, from which China expects to reap massive benefits and financial gains. The earnings potential would support its effort to become a global superpower.

\subsection{Cooperation between the Chinese Government and Private Entities}

Although China has ramped up its attempts to spread its digital currency widely before the winter Olympics in 2022, the government claims that undermining the position of the country's "tech titans" in the mobile economy is the last thing it wants to do (Brunnermeier et al., 2019).

Digital currency is already in broad circulation in China. China's payment system is largely dominated by the WeChat and Alipay digital wallets, with hundreds of millions of Chinese using their mobile payment services. Mobile payment and other digital systems have prioritized meeting a narrow set of design requirements, including increasing transaction speed and lowering the cost of use.

However, funds have a broader range of informal and subtle applications (e.g., among friends and microenterprises) (Kaye et al., 2014). These applications could modify the interactions that users anticipate from digital currencies, such as to whom money should be sent, who transfers the 
money, when it is delivered, under what conditions money can be transmitted, and what money can be used for (Kow et al. 2017).

The question is how the public and private sector $\mathrm{n}$ general or specifically payment systems/banks can further increase their dominance in the international market. The relationship between mobile payment and digital currency platforms in China is one in which the latter serves as a "backup" for WeChat Pay and Alipay. It is not clear how this relates to payment systems. The digital workforce requires enterprise-class software capabilities comparable to those found in the private sector. As Tencent and Alibaba expanded beyond mobile payments into investments, insurance, financial services, and online banking, establishing control became critical for Beijing (Olsen et al. 2012). Their rise to prominence as market leaders targeted management finance for accessing free-roaming internet. This is linked to China's large state-owned banks' challenges with entrepreneurs to compete.

The government acted quickly in canceling the initial public offering planned in October 2020 for Alibaba's financial affiliate, Ant Group, and levying heavy fines on various technology companies for anticompetitive behavior (including a fine on Alibaba of $\$ 2.8$ billion). In addition, WeChat and Ant Group were sharply reminded of their obligation to comply with applicable regulations and laws. Other major internet companies were also targeted, most notably, just after its IPO, the ridehailing firm Didi Global was investigated by the Cyberspace Administration of China for violations of national-security, cybersecurity, and data-security laws for proceeding with a US share sale (Mark, 2021). 


\section{Cryptocurrency versus Digital Currency}

The emergence of digital currency is linked to the growth of cyberspace and its potential in recent years. Worldwide finance has been affected by two breakthroughs: the invention of cryptocurrency and the introduction of CBDCs. Cryptocurrency is a type of digital currency whose value is determined by the laws of supply and demand (Aysan et al., 2020). It is based on blockchain technology and operates according to its own rules, as it is not regulated by any central authority. The underlying goal of cryptocurrency is to create a market for digital currency absent of state intervention. Free market advocates believe that the market should be able to determine its own optimal point of equilibrium, in a decentralized monetary system based on cryptocurrency (Crandall, 2019). Satoshi Nakamoto is believed to be a pseudonym for a programmer or perhaps a group of programmers, who invented the first cryptocurrency, Bitcoin (Stifter, Judmayer, Schindler, Zamyatin, \& Weippl, 2018).

Cryptocurrency platforms allow people to trade anonymously and without any restrictions from a central authority. In the eyes of a small investors, the benefits seem huge, but the untraceable nature of these transactions also raises security concerns. Policy makers fear that this kind of financial transactions makes countries vulnerable to a threat of financing terrorism and other criminal activities (Choo, 2015). For instance, according to the US Department of Justice, a large amount of evidence shows that terrorist organizations such as Al Qaeda and ISIS use cryptocurrency to fund their activities (2020). The amount of money laundering has also increased since the introduction of modern-day cryptocurrency (Kaplan, 2021).

The second breakthrough is the introduction of CBDCs, with which many central banks are experimenting in order to maintain their relevance in the financial system, as it becomes more digitized in general. Faced with the fact that, in recent years, cryptocurrencies have attracted 
investors, central banks needed to be able to present a competitive alternative using the latest technology to enable prompt and secure transactions for its customers. The introduction of CBDCs was, therefore, inevitable. CBDCs are highly centralized, as the flow of money is controlled by the central bank. CBDCs serve multiple purposes, as they can be used for exchange transactions between banks and other financial institutions as well as for daily transactions between businesses and consumers. Unlike with cryptocurrency, with $\mathrm{CBDCs}$ transactions cannot be made anonymously, and those transactions can be tracked. Like Bitcoin, CBDCs are virtual, but, unlike Bitcoin, which is issued by a private enterprise, they are issued by the state and function like traditional currencies (Prasad, 2021).

The underlying difference between CBDCs and a cryptocurrency that operates freely and relies on the laws of supply and demand is the level of oversight and regulation to which they are subject. CBDCs are highly centralized, as they are monitored by the central bank, which maintains complete control over the supply of digital currency in the economy using contractionary and expansionary policies (Duarte, 2019). One way in which the central bank can use an expansionary policy is by lowering short-term interest rates to increase the money supply; conversely, if it raises interest rates, consumers have a greater motivate to save money, which tends to reduce the flow of money in the market. Nakamoto devised Bitcoin in opposition to this monetary policy function of fiat money. Moreover, central banks can use CBDCs as part of their goal to regulate the economy in such a way as to enable higher growth while maintaining economic and financial stability (Aysan et al., 2014).

Cryptocurrencies, by contrast, are based on blockchain technology and are highly decentralized, with no central authority responsible for maintaining oversight or proper operations (Andryushin, 2018). Rather than having a single entity retaining control over the money used for transactions- 
that is, the central bank in the case of CBDCs - the power supporting cryptocurrency is distributed across a vast network of individuals. Because they are vulnerable to changing economic conditions and the opinions of influential entities that can manipulate the market to their advantage, and their value is constantly fluctuating, cryptocurrencies are highly volatile, and investment in them is very risky (Borgonovo, Cillo, Caselli \& Masciandaro, 2018).

Central banks have regulations in place to control fluctuation in the value of their CBDCs. Because CBDCs are backed by a credible authority enforcing these regulations, they are considered a secure investment. Moreover, the central bank controls the supply of CBDCs, which can be increased or decreased based on the prevailing economic conditions, whereas the supply of cryptocurrency is limited by the quantity made available ("mined") at its launch. Despite their limited supply, a wide range of cryptocurrencies is globally available, with more than 6,500 kinds traded on the market as of September 2021, though many of them have little trading volume. By contrast, only few CBDCs are currently offered. Another factor that differentiates a CBDC from a cryptocurrency is the level of personal verification required for purchase. A central bank requires complete verification for someone interested in investing in it, but purchasing cryptocurrency is subject to no such verification of the investor's identity. This right to anonymity is viewed as making investment more democratic but has far-reaching economic and security implications as it opens the door to criminal activities (Dyntu \& Dykyi, 2018).

\section{Is the Digital Yuan a Threat to the US Dollar?}

The convenient and cost-saving nature of digital transactions is rapidly driving the world toward a cashless society that has no need for physical money. Although the market is currently dominated by cryptocurrency issued by private entities, CBDCs are also gradually gaining momentum, raising 
concern in many countries that fiat money is reaching obsolescence. The coronavirus pandemic, which emerged in China in 2019, also proved to be a major catalyst behind China's swift movement toward a digital currency as people began to prefer contactless payment. As of 2021, more than 80 percent of payments in China are made on smartphones, the world's highest rate of mobile payment adoption (Knoerich, 2021). The new digital currency system not only influences the monetary system in China but also has the power to transform the global monetary system. At present, major transactions around the world are denominated in US dollars even when neither party uses the US dollar as a local currency. The prices of major commodities, such as oil and petroleum, are also denominated in US dollars. Hence, China's launching of a CBDC raises a question about whether the digital transformation of global finance led by China can be considered a threat to the leading role currently held by the US dollar.

China seeks to challenge the political and economic dominance of the United States over the world through the introduction of its own digital currency in the form of a DCEP. The US dollar is currently the most highly sought currency in terms of its use as a reserve currency as well as a global currency for trade and investment. The development of the DCEP is intended to reduce the impact of the US dollar in the international payment system as it will help the RMB to be circulated more widely. The PBOC began its digital currency efforts in 2017, earlier than in any other country. China conducted trials of its digital currency for just three years, becoming the first country to do so in April 2020. China's first-mover advantage is significant, as it is a key to global dominance, and scholars believe that this early development of the DCEP will help China in internationalizing its currency (Knoerich, 2021). 
The efforts by the Chinese government to internationalize its currency trace back to 2009, when the global economy faced setbacks due to the financial crisis. Therefore, development of the DCEP is less a product of the growing importance of cryptocurrency than of China's efforts toward RMB internationalization (Peters, Green, \& Yang, 2020). The PBOC issued a white paper on the subject, highlighting the country's progress, and looked optimistically to a future in which its currency would attain global status. It further stated that countries that have friendly ties with China strongly desire to use the RMB as an alternative to the US dollar in the global market, especially those that lie along the Belt and Road (Lin, Xiao, Liang, \& Zhang, 2017). Thus, the Belt and Road Initiative (BRI) can be seen as a prime driver of RMB internationalization and part of the effort to replace the US dollar in the global market. In 2016 China reached yet another milestone when the RMB became part of the basket of currencies with special drawing rights, joining the US dollar, the euro, the Japanese yen, and the British pound (Zhang, Wang, Wei, \& Zhao, 2021).

Mathews and Selden (2018) claim that China's efforts seem less likely to be aimed at internationalizing their currency and more likely to be focused on replacing the dollar as a global currency. In the international monetary system, the RMB and the US dollar work at cross purposes, therefore, the progress toward RMB internationalization comes at the expense of the US dollarthat is, greater demand for the RMB means less demand for the US dollar. Economists argue that the US has the resources necessary for surpassing China in the market for digital currency, but it does not yet seem to be pursuing such a project (Aiden \& Mason, 2021).

China's position as the world's largest exporter gives it an edge over the US in its efforts to internationalize its currency. Based on DCEP, China expects to offer its trading partners simplified payment methods - that is, direct transactions denominated in RMB can take place without involving a third-party currency exchange (US dollar in this case). Conducting transactions in this 
way eliminates the need to incur the cost of currency exchange, further streamlining imports and exports for China and its trading partners. In addition, the Chinese government can use its influence in the international market to accelerate the process of dethroning the US dollar. Countries that particularly benefit from China's growing economic influence and those that are currently troubled by the US dollar would be inclined to participate in challenging the hegemony of the dollar (Hoffman et al., 2020).

China's endeavor to challenge the eight-decade-long status quo has made great strides since the development of DCEP, but the Chinese government still has a long road ahead. Although the increase in the rate of growth in the share of foreign exchange reserves denominated in RMB appears to be significant, it does not have much impact when compared to the growth rate of reserves denominated in US dollars. US dollars comprise 61.79 percent of the total foreign exchange reserves, compared with the share of the RMB, 2.01 percent (IMF, 2020). Nevertheless, WeChat Pay and Alipay have facilitated digital payment so much that almost the entire payment system in China now operates cashless. The introduction of DCEP can therefore help spread this digital payment system outside China as well as challenge the supremacy of the US dollar. Mobile payment systems are similarly widespread in the US, for instance, ApplePay, GooglePay, and PayPal. So, the supplanting of dollar hegemony by the Chinese digital payment system is a distant prospect.

Despite China's rigorous effort to internationalize its currency, the RMB still ranks lower than other major reserve currencies in the world. According to data compiled by the International Monetary Fund (IMF; 2020), the US dollar is still the currency most in demand, as it ranks first in all respects: in the share of global payments, the share of foreign exchange market turnover, and the share of allocated foreign exchange reserves. The US dollar and the euro are far ahead of the 
RMB in all these respects, making them difficult to dethrone as leading currencies, considering how embedded they are in the international financial system. Furthermore, the attractiveness and usability of a currency are defined by the ease with which it can be used all over the world. Essentially, the exchange among countries of major commodities such as oil and petroleum is invoiced in US dollars, and as long as their prices are denominated in dollar terms, the likelihood that a new currency will make a dent in the international market remains rather low. In the international payment market, 40.33 percent of payments were made in US dollars and only 1.76 percent in RMB, which further highlights the gap between the currencies in their attractiveness and usability (see Table 2; SWIFT, 2020).

Similarly, although DCEP seems to be a promising investment for China, it has little ability to blunt the dominance of the US dollar and take over the international payment system. If anything, the development of DCEP can help lay the foundation for an economic battle against the US and other global leaders.

Table 2. Global use of the renminbi

\begin{tabular}{llll}
\hline Currency & $\begin{array}{l}\text { Share of global } \\
\text { payments } \\
\text { June 2020, \% (Rank) }\end{array}$ & $\begin{array}{l}\text { Share of foreign exchange } \\
\text { market turnover } \\
\text { April 2019,\% (Rank) }\end{array}$ & $\begin{array}{l}\text { Share of allocated } \\
\text { foreign exchange } \\
\text { reserves } \\
\text { Q1 2020, \% (Rank) }\end{array}$ \\
\hline USD & $40.33(1)$ & $88.3(1)$ & $61.99(1)$ \\
EUR & $34.10(2)$ & $32.3(2)$ & $20.05(2)$ \\
GBP & $7.08(3)$ & $12.8(4)$ & $4.43(4)$ \\
JPY & $3.74(4)$ & $16.8(3)$ & $5.70(3)$ \\
CNY & $1.76(5)$ & $4.3(8)$ & $2.02(5)$ \\
\hline
\end{tabular}

Source: SWIFT (2020).

The theory that the introduction of DCEP will alter the course of the entire financial system has misled the world into believing that the RMB could rival the dollar in the long run. However, this 
theory fails to acknowledge that only the mode of the currency is being switched from physical to digital. No new actual currency is being launched, therefore, all the factors that apply to the physical RMB also apply to the digital RMB (Paulson, 2020). For example, the capital controls and the highly illiquid nature of the Chinese monetary market hinder wider acceptance of the RMB as a global currency. Therefore, although the development of DCEP might have a significant impact on the international monetary system because China has a first-mover advantage in issuing CBDCs, it does not pose a real threat to US dollar dominance any time soon.

\section{Conclusion}

By rolling out its $\mathrm{CBDC}$, China has undoubtedly gained a first-mover advantage. Its large population and the widespread familiarity with digital and cashless payment have helped the PBOC to offer its CBDC earlier than other countries. This first-mover advantage also puts China in a privileged position in determining the future direction of financial technologies. An early launch of the digital yuan would help China to internationalize its currency and to challenge the hegemony of the US dollar in the global financial system. China's initial focus is international payments, but in the medium and long term, it wants to promote the RMB as an international reserve and investment currency as well. The successful internationalization of the digital yuan will require China to win the confidence of global users in the strength of the Chinese economy, financial system, and the functionality and security of the digital yuan. Despite these advantages, China also faces challenges in achieving these goals. The outcome depends on how the US responds and how the US and Chinese economies evolve in the future. The US would be able to catch up with a digital currency quickly, as the US is already a strong fintech power, and most Americans already use electronic payment systems for most transactions. This might reduce the extent to which China could capitalize on its first-mover advantage. To catch up with China's 
digital currency, the US must develop its CBDC in the short term and needs to play a genuinely positive and constructive role in multilateral economic affairs.

An increase in the use of DCEP also has far-reaching implications for other countries, especially other Asian countries. China's deep connections with other Asian countries are reflected in their mutual trade. The frequent travel and numerous investment opportunities, including inward and outward foreign direct investment, are signs of the extent of transactions between them. Hence, wider use of China's DCEP implies that these transactions will no longer be denominated in US dollars but, rather, in digital yuan. This shift in currencies might appear troublesome for some of China's trading partners because it might introduce constraints on these countries in the choice of currency needed for transactions (Randhawa, 2020). Factors such as the cost of currency conversion and the profitability of holding international currency reserves greatly affect a country's choice of currency to be used when conducting an international transaction. As China's DCEP approaches internationalization, the country's trading partners, particularly Asian countries, fear that they will be deprived of that choice and will be forced to conduct transactions only in RMB.

In addition, the global infrastructure development strategy employed by China in the form of the BRI also appears to have radical implications for Asian integration. The BRI claims to create a great deal of investment in more than 70 countries across Asia, Europe, and Africa. Asia, as a large recipient of BRI investment, is heavily affected by the Chinese government efforts to promote RMB-denominated lending, such as the opening of the Asian Infrastructure Investment Bank (Yefremov, 2021). However, many developing countries, especially those with a soft currency, could benefit from DCEP instead because of the swift and simple nature of transactions that use it. The establishment of Ant Financial and Tencent across Asia has introduced a prompt payment 
system in several countries (Ferguson \& Parker, 2020). In conclusion, the development of DCEP has profound implications for Asian countries that will unfold after the Chinese government successfully makes its mark in the global financial market.

\section{References}

Aiden, B., \& Mason, O. (2021). Cryptocurrency and the future currency in the United States of America. Journal of Finance and Accounting, 5(2), 10-17.

Andryushin, S. A. (2018). Change paradigm of money system: from centralization to decentralization. Actual Problems of Economics, 12(2), 204-219.

Auer, R. A., Cornelli, G., \& Frost, J. (2020). Rise of the central bank digital currencies: drivers, approaches and technologies. No. 8655. CESifo Working Paper.

Aysan, A., Kayani, F., \& Kayani, U. N. (2020). The Chinese inward FDI and economic prospects amid COVID-19 crisis. Pakistan Journal of Commerce and Social Sciences, 14(4), 10881105.

Aysan, A.F., Khan, A., Topuz, H., \& Tunali, A.S. (2021). Survival of the fittest: A natural experiment from crypto exchanges. Singapore Economic Review. 1-20

Aysan, A.F., Sadriu, B., \& Topuz, H. (2020). Blockchain futures in cryptocurrencies, trade and finance: A preliminary assessment. Buletin Ekonomi Moneter Dan Perbankan. 23(4), $525-542$.

Aysan, A.F., Fendoğlu, S., \& Kilinc, M. (2015). Macroprudential policies as buffer against volatile cross-border capital flows. Singapore Economic Review. 60(01), 1550001. 
Aysan, A. F., Ulu, M. F., \& Ünay, S. (2015). Post-Crisis Shifts in Macroeconomic Management and Central Banking: Could Consumption Planning Emerge as a Macro-Prudential Tool?. In Economic Planning and Industrial Policy in the Globalizing Economy (pp. 355-375). Springer, Cham.

Aysan, A. F., Fendoglu, S., \& Kilinc, M. (2014). Managing short-term capital flows in new central banking: unconventional monetary policy framework in Turkey. Eurasian Economic Review, 4(1), 45-69.

Bech, M. L., \& Garratt, R. (2017). Central bank cryptocurrencies. BIS Quarterly Review September.

Borgonovo, E., Cillo, A., Caselli, S., \& Masciandaro, D. (2018). Between cash, deposit and Bitcoin: Would we like a central bank digital currency? Money demand and experimental economics. April 1. BAFFI CAREFIN Centre Research Paper, 2018-75.

Cain, G. (2016). Bad governance in Zimbabwe and its negative consequences. Downtown Review, 2(1), 1-8

Canton, H. (2021). Bank for International Settlements-BIS. In The Europa Directory of International Organizations 2021 (pp. 468-470). Routledge.

Chen, Y., \& Bellavitis, C. (2020). Blockchain disruption and decentralized finance: The rise of decentralized business models. Journal of Business Venturing Insights, 13, e00151.

Choo, K. K. R. (2015). Cryptocurrency and virtual currency: Corruption and money laundering/terrorism financing risks?. In Handbook of digital currency (pp. 283-307). Academic Press. 
Crandall, J. (2019). Blockchains and the "chains of empire": Contextualizing blockchain, cryptocurrency, and neoliberalism in Puerto Rico. Design and Culture, 11(3), 279-300.

Davoodalhosseini, S. M. (2021). Central bank digital currency and monetary policy. Journal of Economic Dynamics and Control, 104150.

Duarte, C. B. (2019). Alternative Monetary targets, instruments and future monetary policy frameworks. Review of Political Economy, 31(4), 582-601.

Ducas, E., \& Wilner, A. (2017). The security and financial implications of blockchain technologies: Regulating emerging technologies in Canada. International Journal, 72(4), $538-562$.

Dyntu, V., \& Dykyi, O. (2018). Cryptocurrency in the system of money laundering. Baltic Journal of Economic Studies, 4(5), 75-81.

Ferguson, J., \& Parker, M. S. (2020). Perspectives on Chinese digital RMB strategy.

Hoffman, S., Garnaut, J., Izenman, K., Johnson, M., Pascoe, A., Ryan, F., \& Thomas, E. (2020). The flipside of China's central bank digital currency. Australian Strategic Policy Institute. Policy Brief Report No. 40/2020.

Kahn, C. M., \& Roberds, W. (2009). Why pay? An introduction to payments economics. Journal of Financial Intermediation, 18(1), 1-23.

Kaiser, B., Jurado, M., \& Ledger, A. (2018). The looming threat of China: An analysis of Chinese influence on Bitcoin. arXiv preprint arXiv:1810.02466.

Kaplan, A. (2021). Cryptocurrency and Corruption: Auditing with Blockchain. In Auditing Ecosystem and Strategic Accounting in the Digital Era (pp. 325-338). Springer, Cham. 
Kaye, J. J., McCuistion, M., Gulotta, R., \& Shamma, D. A. (2014). Money talks: Tracking personal finances. In Proceedings of the SIGCHI Conference on Human Factors in Computing Systems (pp. 521-530.

Kiff, M. J., Alwazir, J., Davidovic, S., Farias, A., Khan, M. A., Khiaonarong, M. T., ... \& Zhou, P. (2020). A survey of research on retail central bank digital currency.

Knoerich, J. (2021). China's new digital currency: Implications for renminbi internationalization and the US Dollar. In The (Near) Future of Central Bank Digital Currencies: Risks and Opportunities for the Global Economy and Society (pp. 145-166). Peter Lang.

Kow, Y. M., Gui, X., \& Cheng, W. (2017). Special digital monies: The design of Alipay and WeChat wallet for mobile payment practices in china. In IFIP Conference on HumanComputer Interaction (pp. 136-155). Cham: Springer.

Lee, D. K. C., Yan, L., \& Wang, Y. (2021). A global perspective on central bank digital currency. China Economic Journal, 14(1), 52-66.

Lin, X., Xiao, Y., Liang, Y., \& Zhang, X. (2017). Research on the belt and road initiatives and strategies of RMB internationalization. Business and Management Research, 6(1), 13-27.

Lo, C. (2021). China's global disruption: From digital currency to COVID-19. In China's Global Disruption. Emerald.

Louie, B. L., \& Wang, M. (2021). China's forthcoming digital currency: Implications for foreign companies and financial institutions in China. Journal of Investment Compliance, 22 (2), $195-200$ 
Mark, J. (2021). Why China's digital currency threatens the country's tech giants. Available at: https://www.atlanticcouncil.org/blogs/new-atlanticist/why-chinas-digital-currencythreatens-the-countrys-tech-giants/ (accessed August 2021).

Mathews, J. A., \& Selden, M. (2018). China: The emergence of the Petroyuan and the challenge to US dollar hegemony. Asia-Pacific Journal, 16(22/3), 1-12.

Mersch, Y. (2020). An ECB digital currency: A flight of fancy? Speech at the Consensus.

Olsen, M., Hedman, J., \& Vatrapu, R. (2012). Designing digital payment artifacts. In Proceedings of the 14th Annual International Conference on Electronic Commerce (pp. 161-168).

Paulson, H. M., Jr. (2020). The future of the dollar. Foreign Affairs, 19. 1-8.

Parn, E. A., \& Edwards, D. (2019). Cyber threats confronting the digital built environment. Engineering, Construction and Architectural Management.26(2), 245-266.

Peters, M. A., Green, B., \& Yang, H. (2020). Cryptocurrencies, China's sovereign digital currency (DCEP) and the US dollar system. Educational Philosophy And Theory, 13(1), 1-7.

Prasad, E. (2021). Cash will soon be obsolete: Will America be ready? New York Times.

Randhawa, D. S. (2020). China's central bank digital currency: Implications for ASEAN.

Stifter, N., Judmayer, A., Schindler, P., Zamyatin, A., \& Weippl, E. (2018). Agreement with Satoshi: On the formalization of Nakamoto consensus.

Töpfer, L. M. (2018). China's integration into the global financial system: Toward a state-led conception of global financial networks. Dialogues in Human Geography, 8(3), 251-271.

Yefremov, D. (2021). Digital yuan on the foreground: Initial conclusions from the Chinese experiment. 
Zhang, B., Wang, S., Wei, Y., \& Zhao, X. (2021). Impact of the RMB Joining in the SDR Basket on Its Internationalization from the Perspective of Risk Spillover. Journal of Systems Science and Complexity, 34(1), 339-350. 